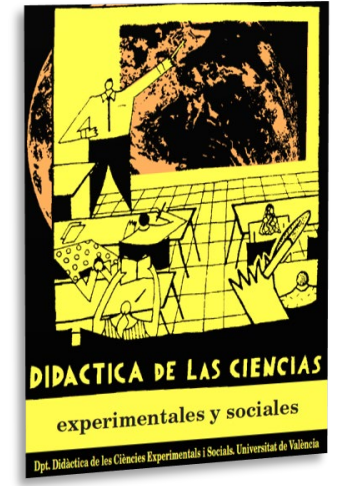

\title{
Experiencia didáctica dentro y fuera del aula: un itinerario interdisciplinar para conocer un barrio de la ciudad de Cuenca
}

\author{
A teaching experience inside and outside the \\ classroom: an interdisciplinary itinerary to \\ know a neighborhood of the city of Cuenca
}

DOI: $10.7203 / D C E S .41 .18420$

\author{
Óscar Serrano Gil \\ Universidad Autónoma de Madrid, oscar.serrano@uam.es \\ ORCID iD: http://orcid.org/0000-0002-4483-2533
}

\begin{abstract}
RESUMEN: La ciudad es un recurso didáctico para los diferentes niveles educativos por el potencial que encierra en sí misma para conocer el espacio geográfico. Por ello, el objetivo principal de este artículo es subrayar el valor que contiene el entorno urbano de la ciudad de Cuenca materializado en el estudio de uno de sus barrios con identidad propia (las Quinientas). La metodología por proyectos ha permitido la participación activa de los alumnos durante las distintas fases de realización del mismo con dos momentos capitales. El primero, mediante la aplicación de una metodología investigativa de las principales características socioeconómicos indagando en los conceptos geográficos previos; y el segundo, a través de una aplicación didáctica sobre el terreno desarrollada en la salida de campo a la barriada. Los resultados obtenidos muestran un mejor conocimiento y una valoración del entorno urbano para ser utilizado como aula al aire libre.
\end{abstract}

Palabras Clave: paisaje urbano, geografía de la percepción, didáctica de la Geografía, Cuenca, itinerario didáctico

ABSTRACT: The city is a teaching resource for different educational levels due to its potential for the understanding of the geographic space. Therefore, the main objective of this article is to underline the value of the urban environment of the city of Cuenca, and, in particular, one of its neighborhoods with a unique identity, "Las Quinientas". The project-based methodology has allowed the active participation of students throughout the different phases of the project, with two key moments. The first one focused on an investigative methodology to search information about the main socio-economic characteristics, investigating the previous geographical concepts; whilst the second one developed a didactic application during a field trip to the neighborhood. The results show a better knowledge and an appreciation of the urban environment as an outdoor classroom.

KEYWORDS: urban landscape, geography of perception, Geography teaching, Cuenca, didactic itinerary

Fecha de recepción: octubre de 2020

Fecha de aceptación: enero de 2021 


\section{INTRODUCCIÓN}

Las Ciencias Sociales, en un sentido amplio de la definición, abarcan los saberes que estudian, por un lado, al hombre y sus actividades en sociedad en clave temporal; y por otro, las interacciones existentes entre el ser humano y el medio acontecidas en cada instante. Ello muestra inherentemente, la riqueza de aprendizajes procedentes del entorno en su conjunto revirtiendo en el estudiante. Por ello, el hecho de diseñar una acción educativa fuera del ámbito de enseñanza habitual implica un ejercicio de enriquecimiento de la realidad circundante del alumno. En este sentido, la acción de conocer y enseñar la ciudad en sentido global, y en particular centrando la atención en un barrio determinado, supone un esfuerzo para comprender la heterogeneidad que encierra en sí mismo desde las variables sociales, económicas y culturales.

De sobra es sabido que, la ciudad siempre ha sido y es un recurso educativo y un elemento de primera índole como herramienta didáctica en el campo de la Geografía considerándose un auténtico laboratorio para la praxis de la disciplina. Así, el fenómeno urbano presenta una larga tradición en la enseñanza por el valor científico y educativo involucrando a docentes de la rama geográfica principalmente pero también de otras áreas de conocimiento lo que subraya el carácter transversal de la misma y la confluencia de las distintas disciplinas aportando conceptos explicativos. Además, ello permite ver a la urbe desde un prisma multidisciplinar convirtiéndose en la perfecta vasija funcional conectando la escuela con la vida. Estudiar la ciudad implica ahondar en una educación en valores mediante estrategias de enseñanza y aprendizaje que respondan holísticamente a las preguntas planteadas por los alumnos sobre el mundo real desde una participación activa (Cambil, 2015). Visto así, la localidad es un aula donde se proyecta un aprendizaje pluridisciplinar. La enseñanza de la geografía establece estrechas relaciones con la vida ciudadana de ahí su importancia en este planteamiento sin olvidar el peso que tiene como materia escolar básica (De Souza, 2020).

El entorno urbano está formado por un sinfín de elementos relacionados estrechamente con procesos de diversa índole (económicos, sociales, culturales, ambientales, étnicos y religiosos, entre otros) (Gurevich, 2009) que remiten al devenir temporal. En un análisis de la ciudad se estudian infinidad de aspectos conectados con el día a día de los alumnos. Son muchas las razones que justifican la comprensión, el aprendizaje y la empatía de los estudiantes de cualquier nivel educativo por el entorno próximo donde viven (espacio vivido). La formación personal se adquiere en el espacio vital, en el entorno familiar y cultural, aspecto que se perpetuará durante su vida de adulto añadiéndose al mismo la impronta de las influencias externas (medios de comunicación y tecnologías de las información -TICs-). De un tiempo a esta parte, se viene asistiendo a una reestructuración de las interrelaciones entre la experiencia, el espacio y el aprendizaje (Vilarrasa, 2005).

La imagen interior del concepto de ciudad es fruto de influencias y experiencias diversas emanadas de múltiples fuentes (lecturas, viajes, vivencias). Huelga decir que la corriente geográfica del Comportamiento y de la Percepción tuvo en la urbe un referente capital como objeto de estudio y más concretamente en las aportaciones de la imagen mental sobre el espacio. Esto mismo fue desarrollado por autores como Kevin Lynch (Lynch, 1960) quien analizó la calidad visual de varias ciudades norteamericanas (Jersey, Boston y Los Ángeles). Esta postura comportamental implica una doble posición complementaria. Por un lado, la urbe no sólo se ciñe al conjunto de edificios y calles regidas por un ayuntamiento, con población densa y dedicada principalmente a actividades no agrícolas. Por otro, en la ciudad también interviene una parte cultural inmaterial y subjetiva. La tríada de elementos (medio ambiente-social-cultural) se extiende al paisaje urbano como plasmación del patrimonio cultural porque muestra "morfológicamente y de manera sintética la evolución y la estructura de la ciudad" (Urteaga y Capel, 1982: 120) en sentido global. 


\section{EL PAISAJE URBANO DE LA CIUDAD Y LA CONFIGURACIÓN DEL BARRIO "OBISPO LAPLANA"}

La estrecha relación existente entre los elementos construidos y la riqueza natural del emplazamiento del casco antiguo de Cuenca fueron motivos para su inclusión en el elenco de ciudades Patrimonio Mundial de la UNESCO en el año 1996. La parte alta de la urbe responde a un entramado medieval fortificado que conserva en buena medida, su trazado original prácticamente inalterado junto a la presencia de numerosos ejemplos de arquitectura civil y religiosa desde los siglos XII al XVIII. El casco viejo se sitúa sobre un escarpe de roca caliza en la confluencia de dos hoces formadas por los ríos Huécar y Júcar. Los criterios de localización y su peculiar topografía fueron determinantes para la declaración como paisaje pintoresco en el año 1963.

El crecimiento de la ciudad generó, en sucesivos momentos históricos, nuevos desarrollos urbanísticos. Debido a los condicionantes del relieve, las ampliaciones de la urbe quedaron prácticamente desligadas del trazado de la trama urbana antigua. Junto a la topografía, circunstancias como la presencia de infraestructuras (ferrocarril) y el diseño de recientes viales, acentuaron la segregación de los nuevos barrios (las "Quinientas", San Antonio, Plaza de Toros y la Fuente del Oro). Algunos de estos sectores se ordenaron en torno a las calles (Reyes Católicos y paseo de San Antonio) que funcionarían como ejes vertebradores.

El barrio objeto de la visita de campo, llamado "Obispo Laplana" pero conocido popularmente por las "Quinientas" debido al número total de viviendas construidas, se sitúa al sureste del centro de la ciudad y fue el resultado de un proceso de intervencionismo en materia de vivienda por parte del gobierno franquista. A mediados del s. XX, este sector presentaba graves problemas de habitabilidad (chabolas) y con el fin de conceder vivienda digna, se propuso la construcción de un Poblado de Absorción con tal fin. Estos Poblados conformaban un conjunto urbano que resolvía las cuestiones de residencia de las familias más humildes localizados en algunas ciudades. Fueron muy utilizados y encontramos bastantes ejemplos al respecto (Fuencarral, Villaverde, Entrevías, Vallecas) (Valero y de Miguel, 1956). En esencia, respondieron a una serie de medidas desarrolladas por la política de vivienda para solucionar las situaciones de infravivienda (chabolas, cuevas) mejorando incluso, con este tipo de planeamiento urbano, las avenidas de acceso y circunvalación.

Mediante un decreto fechado el 3 de abril de 1956 se establecieron los criterios básicos para las construcciones de los inmuebles como la superficie de la vivienda o la distribución en dos plantas. El diseño inicial se completaba con un patio exterior rectangular (García Marchante, 1978). Desde el punto de vista urbanístico, este tipo de intervenciones mostraron un proyecto con identidad propia fácilmente reconocible en el plano y en el paisaje urbano. De hecho, se utilizó una trama urbana dispuesta en damero donde las manzanas de edificios intersectan entre sí dejando la plaza del barrio como epicentro de la vida social. Algunas propuestas didácticas, en el ámbito rural, de este tipo de Poblados se han llevado a cabo (Cano y Navarro, 2012). Creemos que estos motivos justifican un análisis desde el punto de vista educativo y didáctico por las peculiaridades que reflejan en el paisaje de la ciudad además de ser considerado un lugar próximo al alumnado y a su cotidianeidad ayudando así a una explicación lógica de la organización de los espacios (Soares, 2011).

\section{Planteamiento metodológico}

La experiencia didáctica se llevó a cabo en el curso de $4^{\circ}$ del Grado de Maestro en Educación Primaria y dentro de la asignatura "Didáctica del Medio Natural, Social y Cultural" para un total de 57 alumnos durante el mes de diciembre del curso académico 2019/2020 de la Facultad de Educación de Cuenca de la UCLM. Estos estudiantes, como futuros docentes, parten de unos conocimientos mínimos y generales sobre las Ciencias Sociales procedentes de sus estudios previos de Bachillerato y de la Educación Secundaria Obligatoria. Durante su posterior recorrido educativo toman contacto con asignaturas vinculadas directamente a las Ciencias Sociales (Geografía e Historia). Por ello, 
aunque su punto de partida no es cero en sentido estricto, sí es preciso recuperar los contenidos estudiados para situarse en la zona de desarrollo próximo, según Vygotski, y desde ahí practicarlos adquiriendo importancia una evaluación inicial de los mismos.

Desde el punto de vista del método, como armazón hacia donde caminar ordenadamente, en esta propuesta se ha huido esencialmente de las clases magistrales dirigidas por el docente. La apuesta contraria implica ajustar las metodologías a cada uno de los contextos. Por ello, se ha intercalado el trabajo cooperativo y grupal atendiendo a las necesidades en cada momento con la necesaria salida de campo, indispensable como estrategia didáctica (Godoy y Sánchez, 2007) para comprender los fenómenos socio-económicos y culturales a partir de los cambios e interrelaciones acontecidas.

El diseño del trabajo se articula siguiendo la "tríada metodológica" (Tejuca, 2016: 22): trabajo por proyectos-aprendizaje cooperativo-trabajo de campo. El punto de partida se sitúa en la propuesta del docente para realizar una investigación sobre un barrio de la ciudad de Cuenca (Poblado de Absorción "Las Quinientas") idea que encaja en el modelo de proyecto sugerido por el maestro (Butts, 1930), para ejecutarlo dentro y fuera del aula. Para ello, se optó por la aplicación de un formato de trabajo mediante proyectos, corriente de largo recorrido en materia de innovación docente (Gómez y Delgado, 2019; Pozuelos, 2007). Los principios pedagógicos que articulan este modelo emanan de distintas aportaciones como Decroly y los centros de interés que se convierten en las piezas estructurantes de las tareas escolares fomentando la curiosidad del alumnado y consiguiendo así un verdadero currículum integrado frente a la visión puramente aislacionista del mismo. No hay que olvidar, las contribuciones de Dewey que muestran actitudes pedagógicas clave como la eficacia de la acción y el valor práctico de los resultados, traduciéndose en el intervencionismo del alumno en el proceso y en el desarrollo de su propio aprendizaje. La esencia del proyecto responde a un estudio integrado y multidisciplinar del tema de trabajo (una barriada con identidad propia) en el campo de las Ciencias Sociales abarcándolo desde un prisma novedoso y dinámico y superando una visión tediosa de los contenidos y conceptos del área de conocimiento. El estudio de temas cotidianos en sintonía con el trabajo grupal realizado (Pastor, 2004) y la posterior salida de campo al espacio permite, en todo momento, aportar utilidad, interés y sobre todo, motivación en el alumnado debido al cambio de marco en que se produce el aprendizaje.

La segunda de las piezas corresponde con el aprendizaje cooperativo que supone un reto desde el primer momento ya que implica trabajar con compañeros lo que genera, sin lugar a dudas, posibles discrepancias y falta de acuerdos traduciéndose en la compleja gestión de las emociones (Vicent y Luna, 2019). El trabajo colaborativo permite realizar las tareas colectivamente de manera que cada miembro adquiere un determinado rol. Ahora bien, la posibilidad ofrecida por este tipo de aprendizaje ayuda a la competencia de trabajar en equipo, destreza imprescindible en el proyecto planteado y aspecto capital para el buen funcionamiento y la coordinación interna entre los individuos. Se trata de un método interactivo fundamentado en la teoría educativa del constructivismo en donde "el conocimiento es descubierto por la persona que aprende" (Santolaria, 2014: 238)

Y finalmente, el trabajo de campo materializado en la salida y compuesto por los diversos hitos de interés patrimonial, cultural y geográfico (Insa, 2002) que facilitan una lectura interdisciplinar y didáctica. De hecho, es tan rico el proceso de enseñanza-aprendizaje que se canaliza en una doble dirección: estudiante-profesor y profesor-estudiante (Pérez y Rodríguez, 2006) debido a que las experiencias didácticas emanadas de las salidas, en palabras de Lock, "provide a range of learnings opportunities that laboratories cannot suply" (Lock, 1998: 633).

\section{OBJetivos}

Los objetivos principales del trabajo se enumeran a continuación. En primer lugar, con este proyecto se pretende subrayar el valor que encierra el entorno urbano en su conjunto, como herramienta didáctica global pero especialmente atendiendo al análisis y estudio de un sector de la ciudad con personalidad propia como es el Poblado de Absorción "Obispo Laplana” de Cuenca. En 
segundo lugar, afianzar y ahondar en los conocimientos aprendidos por los estudiantes (Grado de Maestro en Educación Primaria) relativos a las Ciencias Sociales poniéndolos en práctica mediante el desarrollo de un itinerario didáctico sobre el lugar en cuestión. No hay que olvidar, en este punto, que la formación generalista de los futuros maestros debe promover la completa integración de las áreas de conocimiento superando las visiones parciales de las mismas. En tercer lugar, mejorar las competencias investigadoras de los alumnos mediante la elaboración de trabajos e informes de carácter socioeconómico utilizado y manejando diversas fuentes de información (estadística y documental, entre otras) así como la manipulación de herramientas tecnológicas (TICs y tecnologías de las información geográfica -TIGs-). Y finalmente, despertar actitudes de valor y respeto por la admiración, conservación y protección del patrimonio construido y edificado, fruto de un momento histórico determinado.

Como objetivos secundarios cabrían destacar que este proyecto encaja dentro del marco global de la asignatura (Didáctica del Medio Natural, Social y Cultural) haciéndose eco, en parte, de los objetivos planteados en la guía docente del plan de estudios. En este sentido se pueden subrayar los siguientes: la ejecución de sencillas investigaciones sobre cuestiones de interés científico dentro y fuera del aula, hecho que se pretendía conseguir mediante las tareas de investigación de los grupos de trabajo; la elaboración de proyectos, de talleres, de materiales didácticos; y el desarrollo de visitas al entorno. La puesta en marcha de este proyecto se incardina dentro de la enseñanza de la geografía la cual, a lo largo de las últimas décadas, se viene materializando especialmente en la búsqueda de aprendizajes significativos interrelacionándolos con la realidad cotidiana (De Souza y De Souza, 2014). Asimismo, no hay que olvidar que la utilidad de las visitas al medio es indiscutible por el mero hecho de que "la escuela tiene que ir a aprender al entorno real, espacio donde se pone en competencia todo lo aprendido" (Morales y otros, 2013: 464).

\section{DESCRIPCIÓN Y DESARROLLO}

La estructura que se mantuvo durante el proyecto responde a las fases propias de un itinerario didáctico (antes, durante y después). Estos tres pasos corresponden con los momentos clásicos que sintonizan con las etapas del trabajo de campo dentro del método científico: formular hipótesis; comprobarlas a través de la experimentación; y extraer las conclusiones a raíz de los trabajos realizados (Vilarrasa, 1999).

Por ello, y siguiendo la premisa del aprendizaje cooperativo, la planificación se recoge de manera sintética en la imagen 1 que permite secuenciar los distintos momentos de participación del docente y del alumnado. La fase del antes correspondería con los números ( 1 al 6); la de durante (con el número 7) y la del después con el número 8. Esto indica que, en el momento previo, se intercalaron intervalos de protagonismo del maestro con los del alumnado. Así, al principio varias sesiones iniciales sirvieron de punto de partida explicativo del proyecto donde papel del docente fue predominante. En cambio, otras sesiones de esta misma fase sirvieron para seleccionar los subapartados de trabajo por parte de los alumnos, donde el profesor actuó de mediador. En total fueron veinticuatro los grupos de trabajo de los que quince era parejas y los nueve restantes agrupaciones de tres alumnos (57 alumnos).

El trabajo autónomo de los estudiantes correspondió con las etapas 4 y 5. Para ejecutarlo partieron de un esquema-tipo con varios momentos: una consulta de las fuentes bibliográficas facilitadas; una elaboración de un documento de Word y un Power Point con las ideas y conceptos más relevantes; y la posterior exposición grupal en clase. El feed back recibido de las distintas exposiciones quedó recogido en la fase 6 que funcionó como retroalimentación en formato grupoclase unos días antes de la salida. La sesión fuera del aula (fase 7) fue la puesta en escena donde los discentes tuvieron que cumplimentar un dossier de campo entregado y realizar encuestas. Tras la finalización del itinerario didáctico, se llevó a cabo el momento de autoevaluación y de resultados facilitando, tras un análisis de los mismos, una visión global de las actividades y del proyecto (fase 
8). En todo momento, la figura del maestro se mostró como guía o auxiliar de todo el proceso aportando, en muchas ocasiones, una perspectiva claramente multidisciplinar desde el punto de vista de las CCSS y de las áreas de conocimiento que comprenden (Sousa y otros, 2016).

IMAGEN 1. Planificación general (fases)

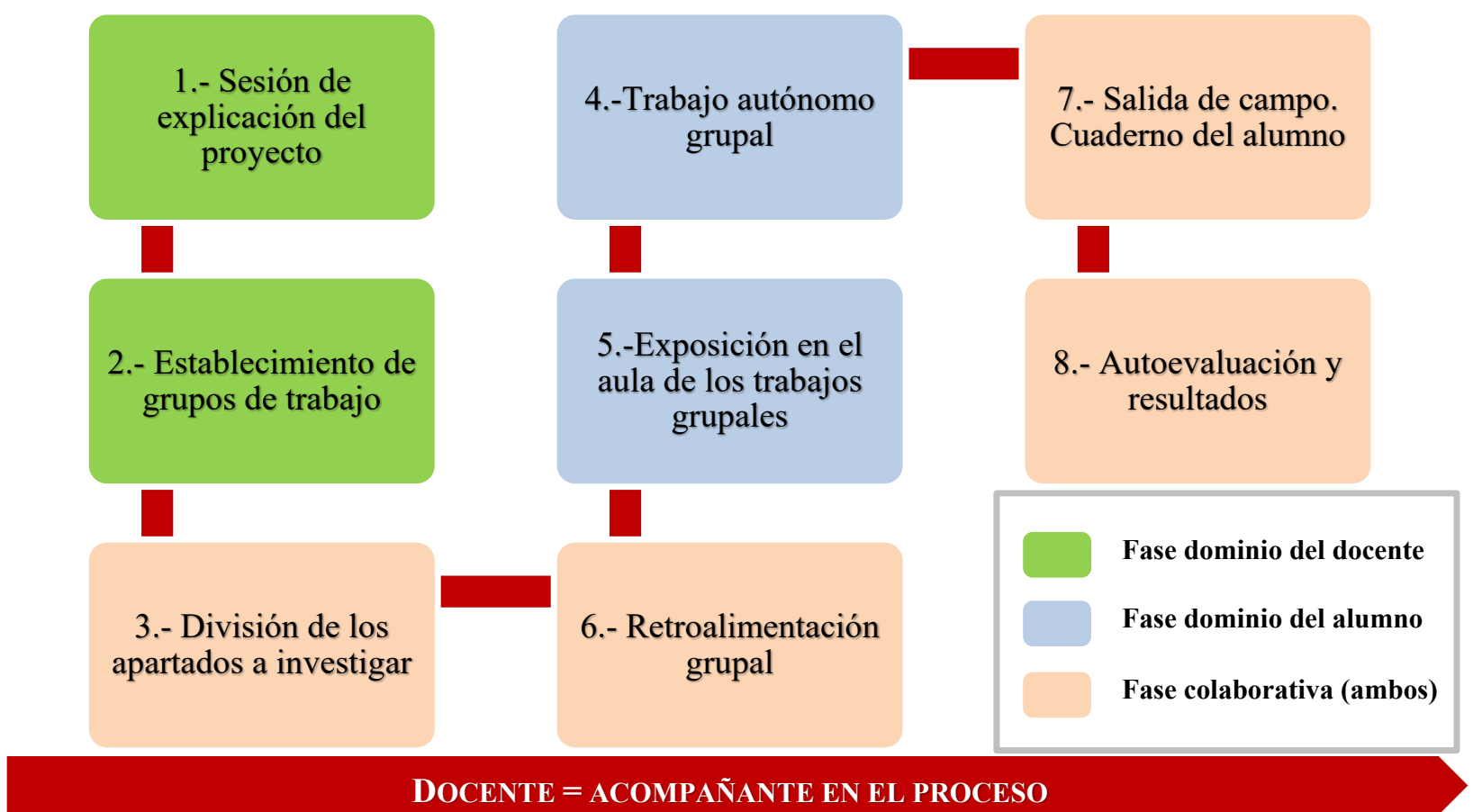

Fuente: Elaboración propia

La división de los trabajos grupales se articuló en dos grandes bloques temáticos: por un lado, uno relacionado con cuestiones de índole contextual e histórica cuyo título fue "Contexto. Cartografía e Historia" y por otro lado, un segundo apartado más amplio titulado "Documentación y estadística".

El primero pretendía establecer el punto inicial de los contenidos básicos refrescando ideas previas latentes en el alumnado (imagen 2). Partiendo de esta premisa, se centró la atención en la investigación de aspectos variados como la localización y el emplazamiento de la ciudad, los tipos de plano y el origen del barrio. Un primer subapartado abarcaba tres temas interesantes para ampliarlos posteriormente: el plano urbano de la ciudad de Cuenca visto en conjunto y comparándolo con las características urbanísticas propias de la zona seleccionada; el estudio y comentario de los tipos de plano urbano dominantes; y el ejercicio de delimitación de la barriada sobre el plano global de la urbe. Otro segundo subapartado focalizaba la atención en la escala territorial próxima como objeto de estudio para estudiar el origen de los Poblados de Absorción, el contexto histórico, la configuración, la estructura urbana y la creación del Poblado en la ciudad. Una vez divididas las temáticas de trabajo, el docente facilitó las diversas fuentes bibliográficas (documentales, hemerográficas y estadísticas) para la consulta de la información y la elaboración de los informes resultantes.

Entre las herramientas utilizadas, a la hora del análisis de los tipos de planos de la ciudad, se recurrió a las TIGs procedentes del centro de descargas del Instituto Geográfico Nacional (IGN) ${ }^{1}$ especialmente a su comparador de imágenes de distintos años. Para documentar la historia y la formación del poblado se consultaron fuentes especialmente bibliográficas y hemerográficas ${ }^{2}$. El

\footnotetext{
${ }^{1}$ Se ha consultado: http://centrodedescargas.cnig.es/CentroDescargas/index.jsp

${ }^{2}$ Se ha consultado: https://prensahistorica.mcu.es/es/consulta/registro.do?control=NUM01000157529 y http://hemeroteca.abc.es/
} 
resultado obtenido de los grupos de trabajos (6 en total) se materializó en la elaboración de Power Points recogidos en la imagen 2.

IMAGEN 2. Bloque 1: "Contexto. Cartografía e Historia"

\section{Plano urbano e historia}

- Principales zonas de la ciudad. Tipos de planos dominantes en la ciudad.

- El plano urbano: trazado viario.

\section{Historia}

- Los Poblados de Absorción.

- Historia y construcción del barrio.

- Prensa histórica y referencias.

\section{Producciones de algunos grupos de trabajo}
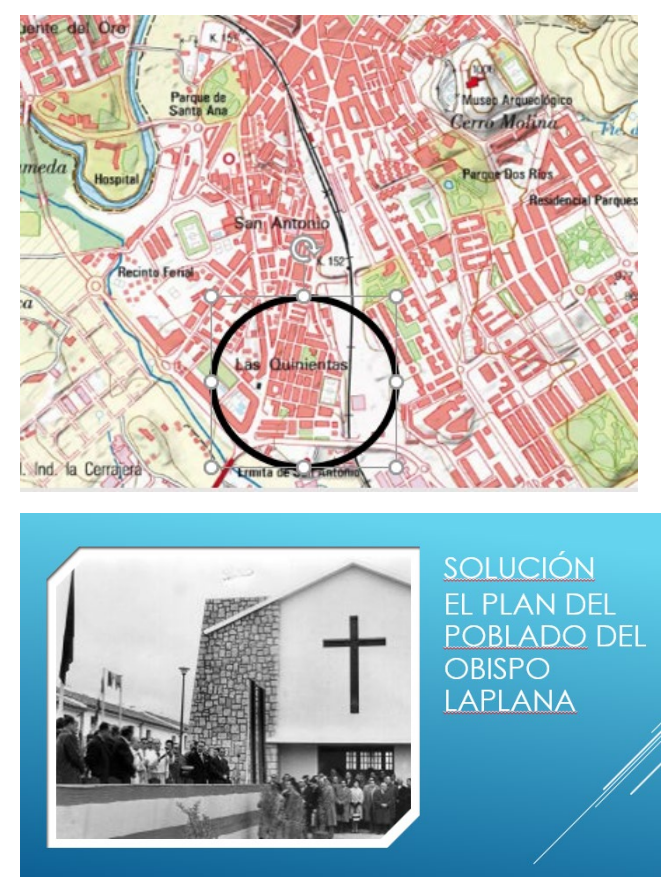

Fuente: Trabajos grupales de los alumnos
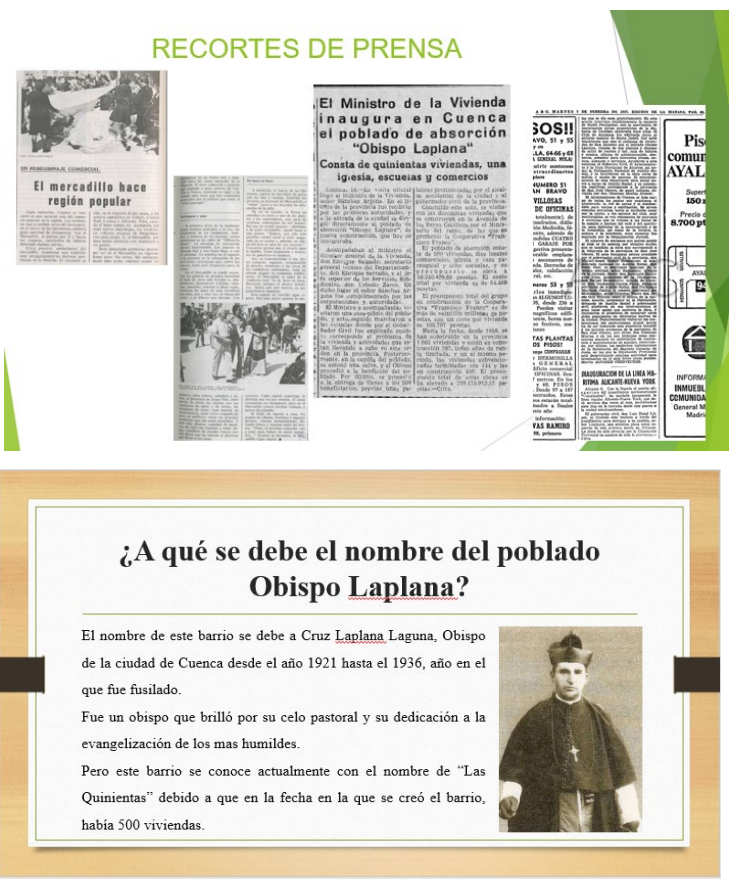

El segundo apartado titulado "Documentación y estadística" (imagen 3) cubría el estudio social y económico en un sentido amplio. Para ello, seis parejas ejecutaron una investigación más exhaustiva sobre cuestiones demográficas, actividades económicas, urbanismo, equipamientos e identidad cultural del barrio. El objetivo era analizar la estructura de la población (jóvenes, adultos, viejos) y otras variables (inmigración, nivel de estudios, renta) recurriendo a la consulta, explotación y postproducción de datos estadísticos procedentes principalmente de dos fuentes: el Instituto Nacional de Estadística ${ }^{3}$ y el Instituto de Estadística de Castilla-La Mancha ${ }^{4}$. A partir de la información extraída, se generaron tablas y gráficos que acompañaron las presentaciones de este segundo apartado.

\footnotetext{
${ }^{3}$ Se ha consultado: https://www.ine.es/jaxiT3/Datos.htm?t=31006 y https://www.ine.es/experimental/atlas/exp_atlas_tab.htm

${ }^{4}$ Se ha consultado: http://www.ies.jccm.es/
} 
IMAGEN 3. Bloque 2: "Documentación y estadística"

Datos e información estadística

- Estructura de la población (jóvenes, adultos y viejos).

- Educación y estudios.

- Población inmigrante.

- Renta de los hogares.

\section{Urbanismo}

- Vías de comunicación importantes, fisionomía dominante, trazado de las calles, anchura, firme.

- Fachadas de los edificios. Semejanzas y diferencias con otros sectores de la ciudad.

- Plazas: distribución, forma y usuarios.

- Toponimia de las calles.

\section{Equipamiento}

- Información de establecimientos. Subsistencia de pequeños comercios y tiendas. Sectores económicos.

- Servicios públicos: ocio, diversión, juego.

- Transportes.

- Instalaciones y equipamientos: sanidad, educación, centros religiosos, otros.

\section{Identidad}

- Fiestas y tradiciones.

\section{Producciones de algunos grupos de trabajo}
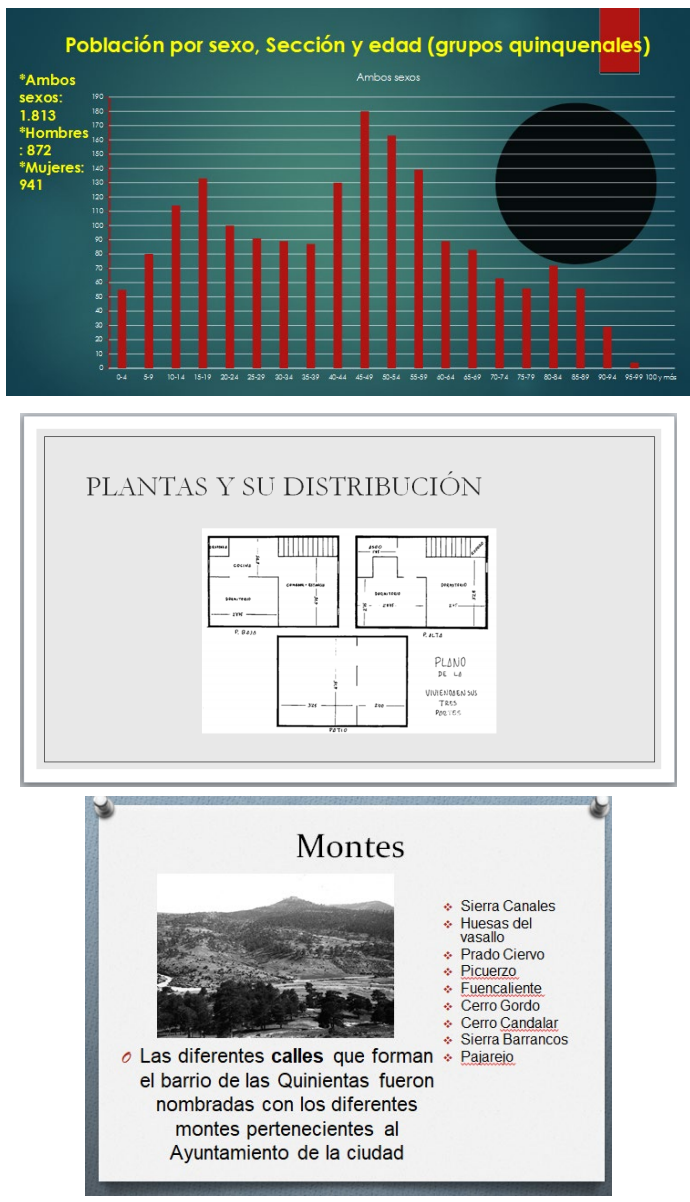
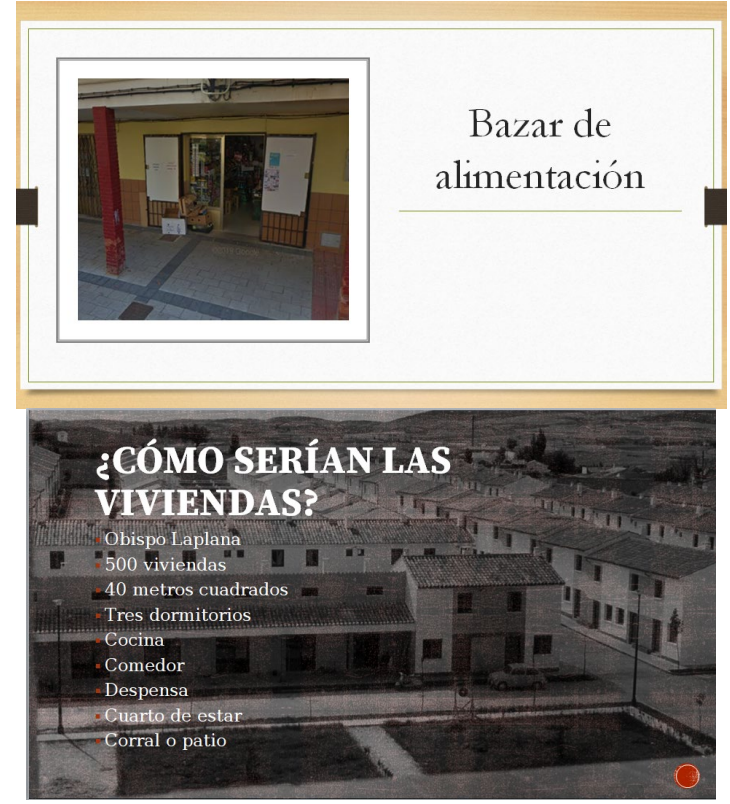

PROGRAMAS DE LAS FIESTAS

Todas las fiestas realizan un programa de festejos, en el que incluye anuncios de los diferentes establecimientos y empresas y la programación.
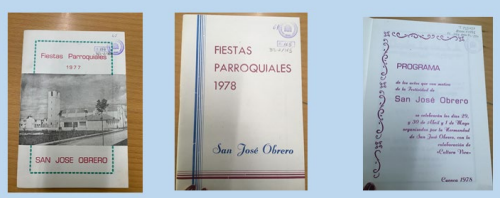

Fuente: Trabajos grupales de los alumnos 
En el apartado de urbanismo, a través de la aplicación Google Maps, se tomó contacto inicial para el estudio de las vías de comunicación y de la tipología de la fachada de las viviendas, además de conocer las características básicas urbanísticas del Poblado. También se utilizó como herramienta auxiliar, previa a la salida de campo, para situar los equipamientos básicos (servicios públicos, educación, sanidad, comercios, industrias) en el plano urbano.

La consulta a la sede virtual del Catastro ${ }^{5}$ facilitó la imagen del plano-tipo de la vivienda de la zona. Este sector de la ciudad presenta la peculiaridad de utilizar en su callejero los nombres de varios montes públicos propiedad del Ayuntamiento de la ciudad lo que se tradujo en un análisis sobre la procedencia de los mismos, hecho prácticamente desconocido para la mayoría de los alumnos, mostrando así el valor que puede tener la toponimia como un recurso didáctico (Gilio, 2015; Mínguez, 2010). Las cuestiones de patrimonio inmaterial de la barriada se estudiaron mediante consultas bibliográficas a varios blogs ${ }^{6}$, libros temáticos ${ }^{7} \mathrm{y}$ folletos que recogían las principales tradiciones como la fiesta de los mayos y la del patrón del barrio.

La salida de campo (fase 7), como pieza fundamental dentro de la disciplina de la Geografía (García Ruiz, 1994) permitió por un lado, poner en marcha los conocimientos vistos en las sesiones anteriores y por otro, contactar directamente con la población del barrio. El recorrido in situ proyectó, sobre el espacio, lo trabajado en el aula mediante los Power Point elaborados. Este paseo didáctico se realizó durante una sesión de mañana (dos horas) con dos explicaciones del docente en lugares estratégicos seleccionados (punto de encuentro inicial y plaza del barrio). En la salida, se pretendía además realizar un trabajo de campo, elemento capital como recurso por cuestiones como la motivación, el conocimiento y la valoración del paisaje urbano además del fomento de los valores sociales (García de la Vega, 2004) que conlleva. En esencia, toda visita que se precie facilita un aprendizaje para ver, para enseñar la mirada y para observar aquello que pretendemos mostrar como enseñantes desarrollando en todo momento destrezas puramente geográficas de ahí su encaje perfecto dentro los objetivos propuestos para la asignatura cursada.

Con el fin de que la visita tuviera un resultado esperado, antes de comenzar el breve recorrido, se entregó un cuaderno de campo en papel por grupo para completarlo. Su posterior devolución comportaría una herramienta más de evaluación. El dossier se estructuró en cuatro actividades principales. La primera titulada "parecidos razonables" ponía el acento en un análisis visual de la evolución del plano urbano a través de dos fotos procedentes de la fototeca digital del IGN. La composición respondía a dos láminas (imagen 5). Una situada a la izquierda fechada entre 1956 y 1957 correspondiente al vuelo americano (serie B) y otra a la derecha relativa al vuelo interministerial de los años 1973-1986. Con el visionado de las mismas, se evidenciaba la localización del barrio de nueva creación y su ubicación en el plano urbano.

En el caso de la segunda actividad, el ejercicio fomentaba las destrezas geográficas de localización. Sobre una imagen de satélite del Plan Nacional de Ortofotografía Aérea (vuelo disponible de 2017) se pretendía delimitar las manzanas del barrio y el trazado de los principales ejes de comunicación con una trama coloreada. Se completaba con geolocalización correcta de un edificio a partir de las coordenadas geográficas facilitadas ayudándose para ello del GPS del teléfono móvil.

La tercera actividad exigía un recorrido por las calles focalizando la atención en la tipología característica de las viviendas y en las actividades económicas del barrio. Una parte del ejercicio precisaba la elaboración de un dibujo, a mano alzada, de la fachada-tipo de las casas (imagen 7) y la otra parte, recogía un inventario de los comercios encontrados durante el paseo. Un subapartado más

\footnotetext{
${ }^{5}$ Se ha consultado: https://www1.sedecatastro.gob.es/Cartografia/mapa.aspx?buscar=S

${ }^{6}$ Se ha consultado: http://cuencaenelrecuerdo.es/SanJoseObrero.php y

https://memoriadecuenca.wordpress.com/2013/12/05/elena-castillejo-toda-una-vida-en-las-500/

7 Se ha consultado: Recuenco, F. (2010). Cincuenta años de un barrio de Cuenca: "Las Quinientas" (1960-2010)". Fundación CCM, 131 p.
} 
de la actividad lo conformaba un ejercicio de síntesis de los principales contenidos trabajados en una salida similar planteada como futuros docentes.

Por último, la cuarta actividad resumía las principales ventajas y desventajas encontradas una vez paseado el barrio. Se trataba de un punto que entroncaba, de alguna manera, con la opinión personal y con la percepción que ellos mismos tenían de este sector de la ciudad antes y después de visitarlo.

Al final del cuaderno, se encontraba la evaluación global de las actividades para lo cual se establecía una valoración apoyada sobre una escala numérica de tipo Likert donde el valor mínimo era 1 y correspondía con "totalmente en desacuerdo" mientras que el valor máximo era 5 que suponía "totalmente de acuerdo".

TABLA 1. Selección de preguntas del análisis DAFO y cuestionario "Percepción del barrio"

\section{Debilidades}

- ¿Hay problemas de comunicación con el resto de la ciudad por falta de transporte público?

- ¿Qué infraestructuras y/o servicios cree que se deberían cambiar en el barrio para atraer a más gente joven a vivir en él?

\section{Fortalezas}

- ¿Piensa usted que la relación calidad- precio de las viviendas, está equilibrada y por tanto es un factor favorecedor para el barrio?

- ¿Qué es para usted lo mejor del barrio? ¿Ha participado usted en estas mejoras? ¿Existen proyectos de mejora del barrio a corto plazo?

\section{Amenazas}

- ¿Se sienten menospreciados o marginados por vivir en este barrio?

- ¿Piensa que las nuevas generaciones se asentarán en este barrio en un futuro?

\section{Oportunidades}

- ¿Tiene la oportunidad de utilizar el transporte urbano o no hay buena combinación?

- ¿Tiene la oportunidad de asistir a un lugar de encuentro o socialización común como la asociación de vecinos?

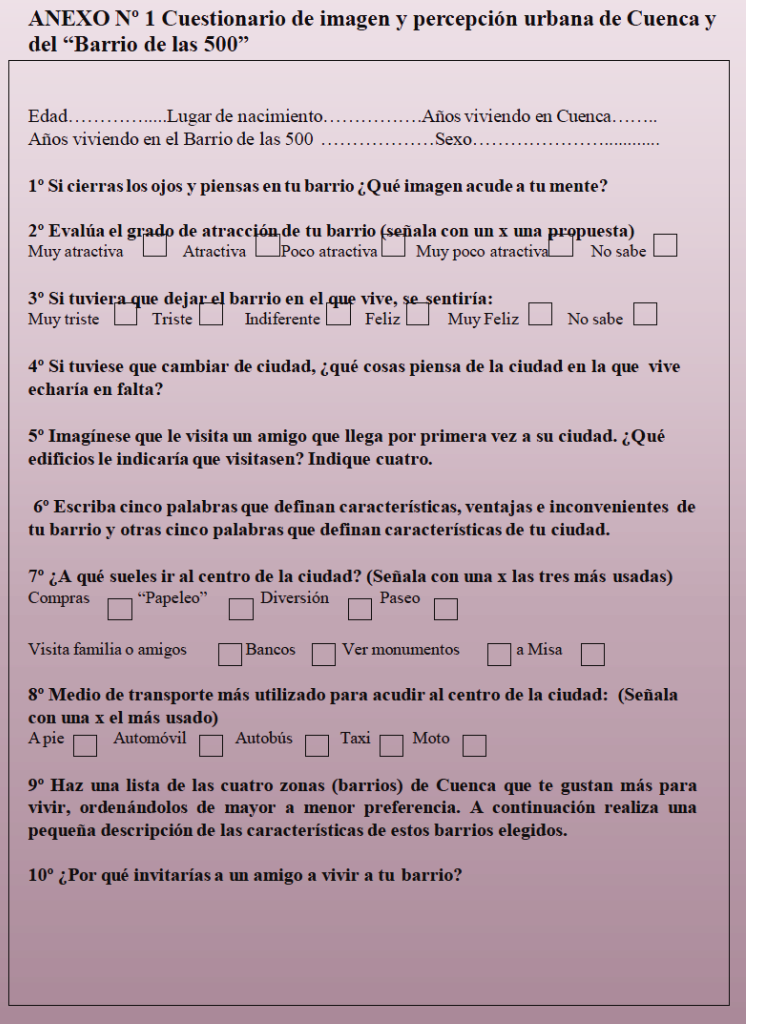

Fuente: Elaboración propia

Una de las ideas fundamentales puesta en marcha fue el contacto con la población local durante la salida de campo, aspecto que se articuló en una doble vertiente. Por un lado, algunas parejas de trabajo (11) realizaron una aproximación a un análisis DAFO del sector urbano para lo cual se diseñó un conjunto de preguntas (14 en total) que conformaron una entrevista destinada a los vecinos abarcando los cuatros aspectos básicos de tipo de análisis (tabla 1): las debilidades (aspectos de falta o mejora en el barrio) (3 preguntas); las amenazas (4 preguntas) focalizando la atención en los problemas, obstáculos y limitaciones encontradas; las fortalezas ( 3 preguntas) subrayando los puntos fuertes; y finalmente, las oportunidades (4 cuestiones).

Por otro lado, un equipo en exclusiva llevó a cabo una encuesta más exhaustiva (diez preguntas) (tabla 1) aplicando, mediante las adaptaciones pertinentes, una metodología de geografía de la percepción (Millán, 2004; Morales, 2012) para obtener una aproximación a la imagen percibida del barrio y de la ciudad de Cuenca por los vecinos del barrio. La entrevista se pudo realizar a tres personas.

Para impulsar la motivación entre los estudiantes durante la salida de campo, el profesor propuso la realización de una gymkana fotográfica con carácter voluntario tomando instantáneas de 
los aspectos más sobresalientes durante el paseo (edificios, construcciones, monumentos). Una vez tenida la foto, los grupos participantes (16 en total) enviaron una imagen seleccionada para participar. Se habilitó una votación telemática vía Google Forms con todas las imágenes en la que los alumnos participasen puntuando cada foto sobre una escala numérica de Likert (valor mínimo 1 y valor máximo 5). Pasado un tiempo prudencial y tras el recuento, se entregaron los premios a las instantáneas más votadas obteniendo como recompensa una ligera subida de la calificación final del proyecto para las parejas agraciadas (imagen 4). La primera y la segunda clasificadas están tomadas prácticamente desde el mismo punto y con la misma perspectiva. Recogen perfectamente la morfología urbana del barrio ya que corresponde con viviendas de baja altura rodeadas de edificios más altos. Junto con la salida de campo, esta actividad fue muy estimulante para los estudiantes con una elevada participación ( 27 valoraciones) teniendo en cuenta la voluntariedad de la misma.

IMAGEN 4. - Formulario de la gymkana fotográfica y fotos premiadas

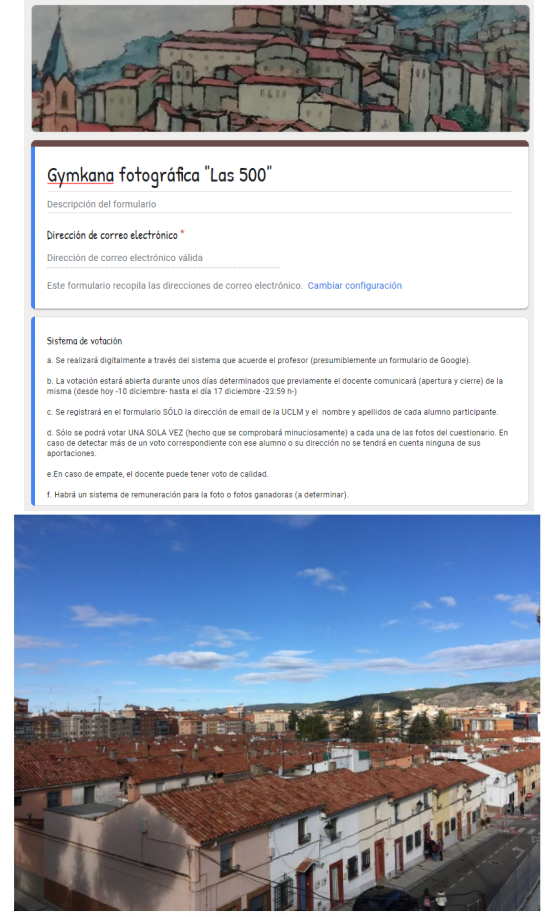

SEGUNDA CLASIFICADA: 70 PUNTOS

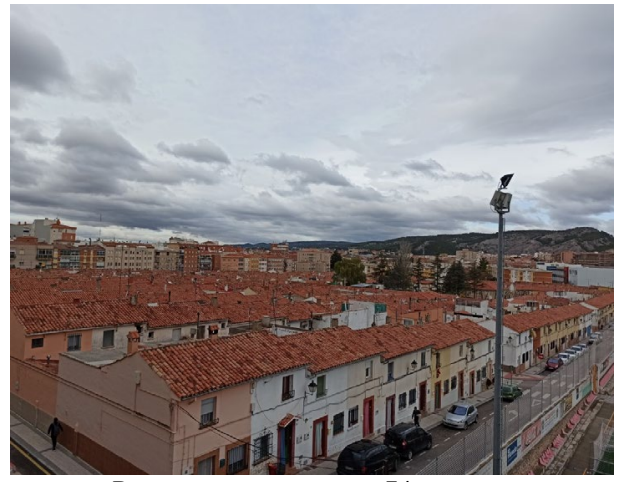

PRIMERA CLASIFICADA: 74 PUNTOS.

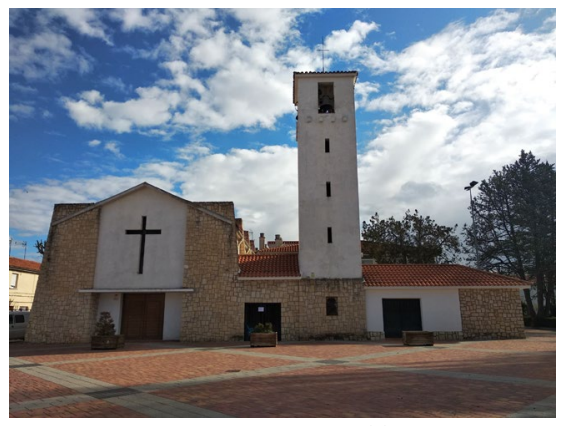

TERCERA CLASIFICADA: 66 PUNTOS

Fuente: Imágenes de algunos alumnos participantes. Diciembre de 2019

\section{RESULTADOS OBTENIDOS}

Los resultados de la puesta en práctica del proyecto en el aula y el desarrollo de la visita muestran el cumplimiento de los objetivos planteados para el conjunto de actividades. La entrega de los cuadernos de campo responde a un ejercicio condensado de observación, atención y destreza. De hecho, la primera actividad resuelta en la imagen 5 se centró principalmente en tareas de localización, orientación y discriminación entre imágenes de vuelos fotogramétricos mostrando una consolidación de los contenidos previamente trabajados diferenciando así, las fechas de las imágenes de satélite y situando la construcción del Poblado en el sector urbano correspondiente. En este sentido, el hecho de leer e interpretar una imagen ayuda a la apropiación de un concepto básico en el estudiante: el de la ubicación (Castellar y Vilhena, 2011). Así mismo, y en clave comparativa, se pretendía distinguir perfectamente la trama urbana del barrio frente a la del resto de los tipos de planos en la ciudad, especialmente en el casco viejo de la urbe. 
IMAGEN 5. - Ejemplo actividad 1 (discriminación de imágenes). Cuaderno de campo

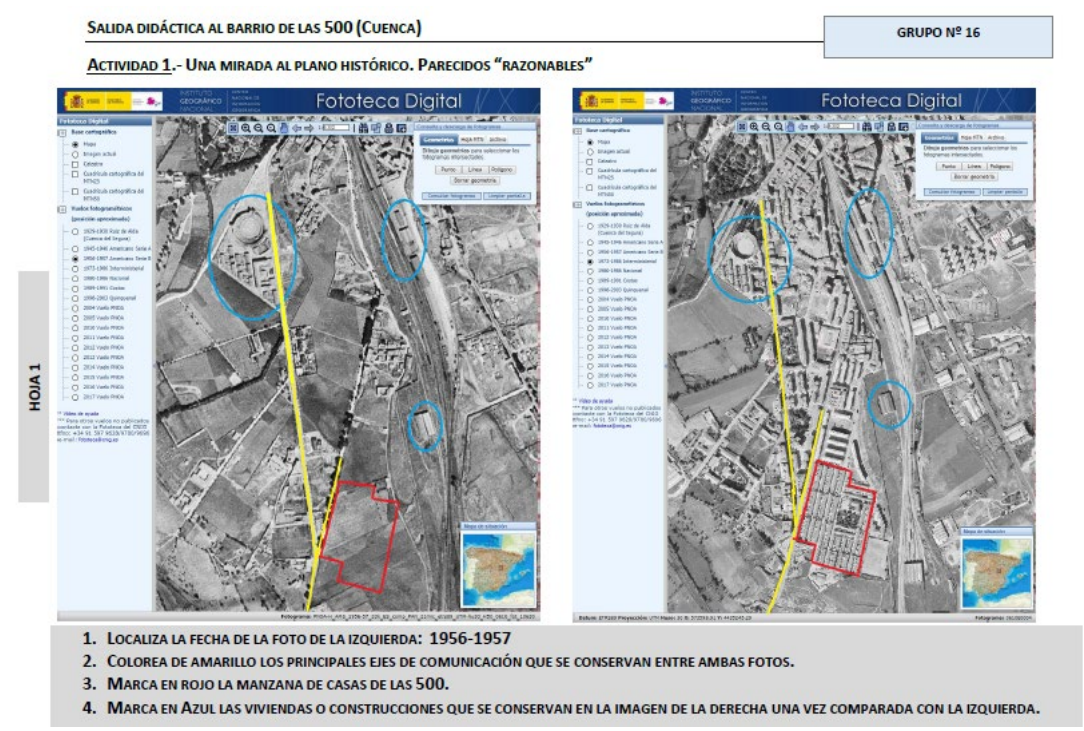

Fuente: Imágenes Fototeca digital CNIG (https://fototeca.cnig.es/). Elaboración propia

En el caso de la segunda actividad (imagen 6) se trabajaban competencias geográficas también sobre la imagen de satélite. El uso de herramientas geográficas como el GPS permitió la práctica de conocimientos de georreferenciación profundizando en la consecución y el desarrollo de las competencias espaciales en los alumnos (De Lázaro, 2013) ubicando uno de los principales edificios del barrio.

IMAGEN 6. - Ejemplo actividad 2 (localización). Cuaderno de campo

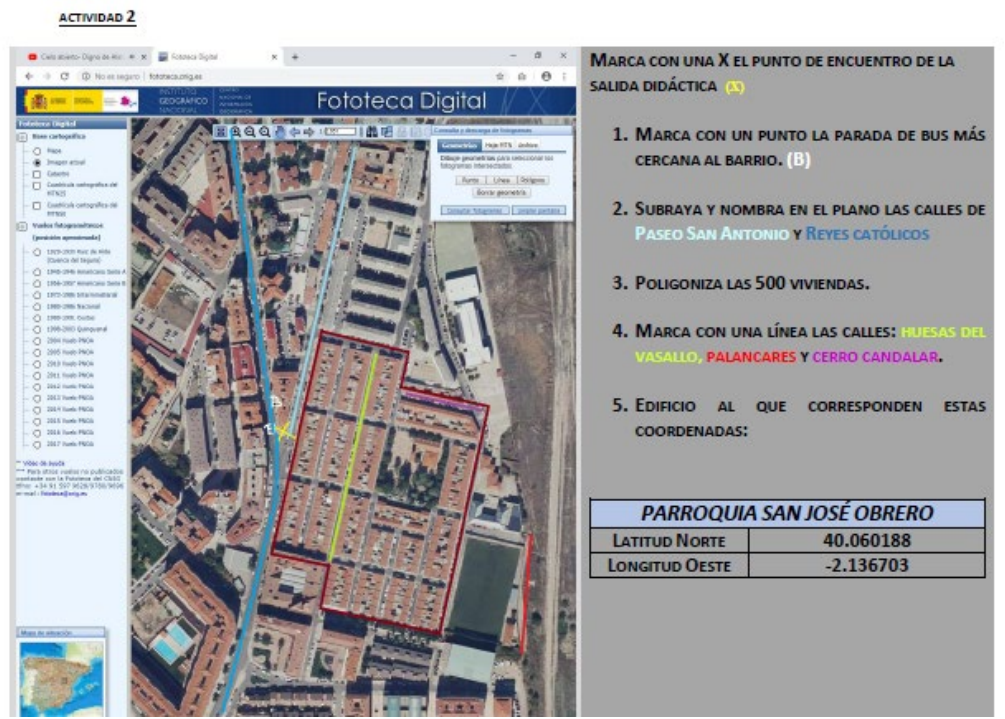

Fuente: Imágenes Fototeca digital CNIG (https://fototeca.cnig.es/). Elaboración propia

Con el fin de conocer in situ los aspectos "físicos" del barrio, el cuaderno contenía un ejercicio para desarrollar la observación y la competencia artística. Éste fue la tercera actividad que se articulaba en tres partes. La primera respondía a la elaboración de un dibujo a mano alzada de la fachada característica y típica de este tipo de viviendas construidas. Con ello, se permitió una doble comparación. Por un lado, las diferencias de este tipo de casa (materiales, alzado) con las de otros sectores de la ciudad; y por otro, la peculiaridad del propio planeamiento urbano como un potencial recurso didáctico (Valverde, 2001) en análisis con otros. Hay que decir que las Quinientas 
respondieron en su origen, a una morfología genuina en el trazado urbano y en las fachadas de las viviendas hecho que, aunque previamente se habían visto en el aula mediante Google Maps, las producciones obtenidas de los estudiantes mostraron un alto nivel de detalle (imagen 7).

IMAGEN 7. - Ejemplos actividad 3 (alzado de la fachada). Cuaderno de campo

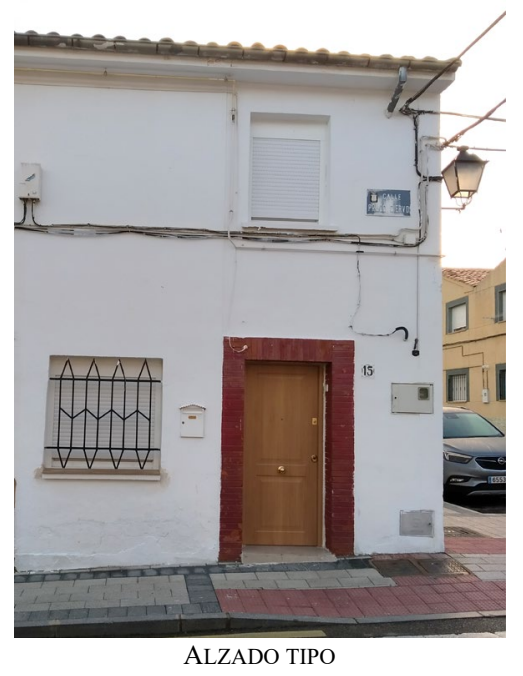

ALZADO TIPO

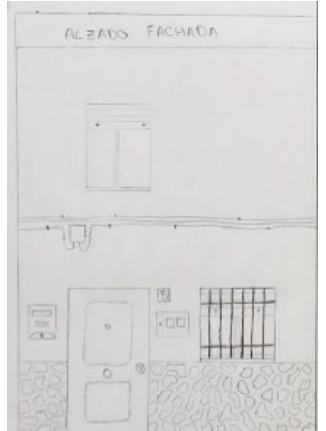

GRUPO 18

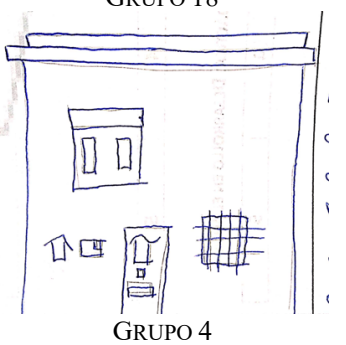

Fuente: Trabajos grupales de los alumnos

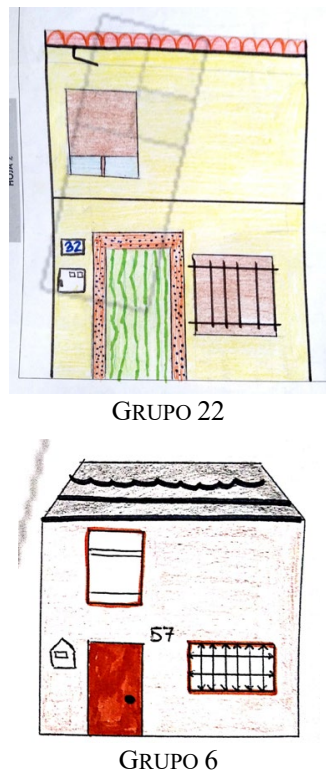

La segunda parte de la actividad analizó los sectores y actividades económicas dominantes en el barrio. Se inventaron, a modo de listado, los principales comercios de la zona lo que mostró el contundente peso del sector terciario (servicios). De hecho, en el ejercicio de observación ocular sugerido, los estudiantes recogieron establecimientos comerciales como peluquerías, bares y cafeterías, tiendas de alimentación y algún bazar. La escasa presencia de algunos servicios básicos está provocando un desplazamiento de los vecinos a calles colindantes (Reyes Católicos y paseo de San Antonio) para atender estas necesidades.

La tercera y última parte recogió una pregunta sobre los contenidos geográficos a trabajar en una visita a un barrio interconectando así lo aprendido en las sesiones en el aula con la puesta en práctica de la salida. En este sentido, los más destacados fueron: el estudio del plano urbanístico, las vías de comunicación, los tipos de vivienda, las cuestiones demográficas, la orientación y localización en el plano, la recogida de información mediante la utilización de fuentes diversas, los sectores económicos, y la historia del barrio.

Para finalizar, el cuarto ejercicio condensó las ventajas y desventajas encontradas en el barrio mediante una tabla con dos columnas. Entre los aspectos positivos, los discentes subrayaron: la cercanía al transporte público y la buena comunicación con otras áreas de la urbe; la proximidad a comercios en calles próximas; la tranquilidad de vivir "como en un pueblo"; el precio asequible de las viviendas (en comparación con otras zonas de la ciudad); la presencia de instalaciones deportivas y culturales; la identidad de barrio y la gratuidad de aparcamiento. En el lado opuesto, las desventajas fueron: la elevada edad de la población que vive en él; la distancia física respecto a la zona universitaria de la ciudad; el predominio del pequeño comercio frente a las grandes superficies; la escasa presencia de actividades de ocio en el barrio; la estrechez del trazado urbano; y la carencia de zonas verdes. El mero hecho de ser un listado de pros y contras permitió tomar conciencia de los problemas sociales vecinales de manera que el conocimiento del medio urbano para los futuros maestros no se resuma meramente en una visión descriptiva sino que pase a una dimensión participativa en el análisis de las cuestiones sociales (Vilarrasa, 2002). 
Estas ventajas e inconvenientes, vistos a simple vista por los alumnos, se completaron con el cuestionario (tabla 1) completado por tres vecinos y por las encuestas del análisis DAFO. En el caso del interrogatorio exhaustivo, la coincidencia entre los entrevistados fue unánime a la hora de definir las características del barrio considerándolo acogedor, humilde, familiar, poblado de gente trabajadora y muy tranquilo. En cambio, hubo más discrepancias a la hora de remarcar el grado de atracción del barrio (dos individuos respondieron poco atractivo y una persona lo consideró atractivo) lo que implica un cierto grado de identificación vecinal con el barrio considerándolo atrayente para vivir aunque sea preciso desplazarse al centro de la ciudad para compras, gestiones de carácter administrativo o visitar amigos. En el análisis DAFO, se extrajeron algunas conclusiones comunes a los entrevistados: dentro de las debilidades se subrayaron las deficiencias en el ámbito de ocio y cultura y la escasez de comercios de productos frescos; entre las amenazas, se acentuaron los problemas de orden social, la presencia de algunos altercados puntuales en el barrio y la marginalidad sufrida por la situación del barrio en el extrarradio; entre las fortalezas cabrían destacar la llegada de población joven atraída por el bajo precio de los inmuebles y el hecho de vivir sintiéndose como en un pueblo; y finalmente, las oportunidades que ofrece la barriada fueron la cercanía al centro de la ciudad y el factor de identidad vecinal.

Respecto a la evaluación de las actividades, se plantearon 5 preguntas puntuándolas sobre una escala de Likert (valor 1 para la más baja y valor 5 para la máxima) en el mismo cuaderno de campo cuyos resultados porcentuales se recogen en la imagen 8 para un total de 57 alumnos. La primera cuestión puntuaba el interés de la temática trabajada (conocimiento y profundización en un barrio de la ciudad) lo que mostró que más de un 50\% concretamente un 52,6\% (30 alumnos) lo valoraron con 4 puntos. Quince puntuaciones le otorgaron el valor $3(26,3 \%)$ y doce alumnos valoraron con 5 esta pregunta $(21,1 \%)$.

De las cinco cuestiones sugeridas, tres aludían a distintos momentos de realización y ejecución del proyecto en su conjunto. Así, la primera de ellas, relativa a la fase previa que englobaba las labores de investigación y de exposición en el aula mostró casi un $60 \%(59,6 \%)$ para una valoración de 4 puntos (34 alumnos) seguida de las 12 calificaciones sobre $3(21,1 \%)$ y de las 11 puntuaciones sobre valor $5(19,3 \%)$. La segunda pregunta se refería al momento del desarrollo del itinerario didáctico y los resultados muestran un predominio (31 respuestas) del 54,4\% para la puntuación 4, seguida del valor 5 (casi un 30\% de alumnos). Y la tercera cuestión, calificaba globalmente la salida desde un punto de vista total atendiendo a todos los aspectos trabajados en la misma. En este caso, casi un 60\% de alumnos (34 respuestas) puntuaron con 4 mientras que un 29,8\% (17 contestaciones) lo hicieron sobre el valor 5 .

La última pregunta a valorar (entrega de materiales) manifestó puntuaciones más repartidas. Aún así un 43,9\% lo valoró con 4 mientras que un 35,1\% (20 alumnos) consideraron un 5 para el dossier de trabajo lo que indica que éste cumplió las pretensiones iniciales como herramienta de apoyo para el paseo didáctico.

Vistos estos resultados encontramos aspectos a mencionar. En primer lugar, se destaca el interés de la temática trabajada ya que las puntuaciones más elevadas (4 y 5) suman un 73,7\% mostrando así la atracción por el proyecto desarrollado tanto dentro como fuera del aula. En segundo lugar, la salida tuvo una buena acogida de manera global ya que casi el $90 \%$ de las respuestas ( 51 alumnos) sumando los valores superiores ( 4 y 5) lo consideró sugerente en la temática y óptimo en la puesta en escena a juicio de los discentes. Hay que tener en cuenta que, con carácter general, los estudiantes universitarios no están acostumbrados a las salidas de campo fuera del aula de ahí que la motivación inicial en la salida ayudó a la elevada valoración de esta pregunta. Así mismo, hay que mencionar, el hecho de que los recursos facilitados se evaluaron positivamente con 45 calificaciones de alumnos en la horquilla 4-5 de la escala lo que implica que es altamente recomendable utilizar, durante los itinerarios didácticos, dossiers o herramientas similares para condensar los conceptos y contenidos trabajados. En la fase del "durante", una de las quejas recogidas fue la escasez de tiempo para completar enteramente el cuaderno de campo ya que se dispuso de dos horas para rellenarlo. 
IMAGEN 8. -Representaciones porcentuales de la valoración del proyecto

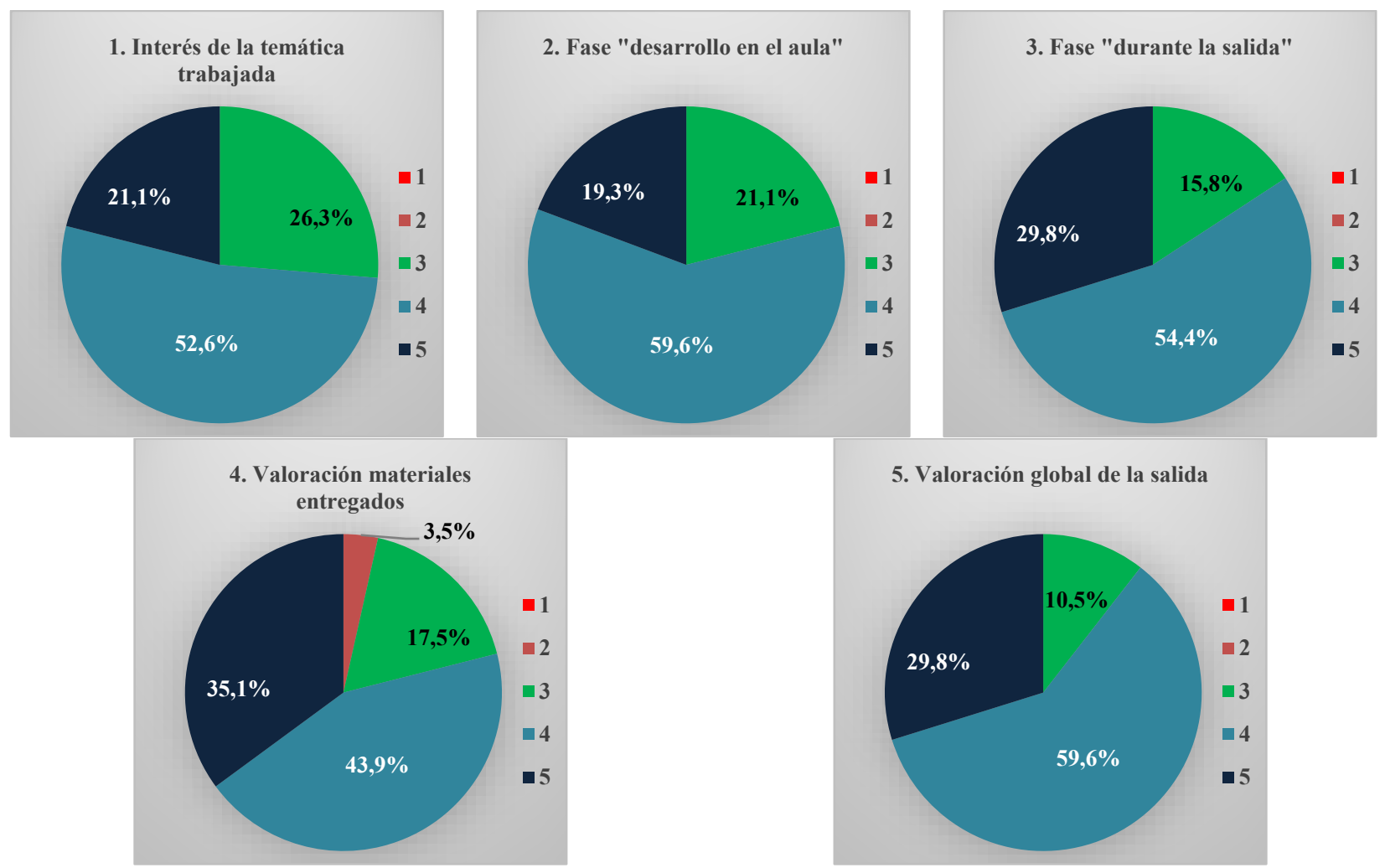

Fuente: Elaboración propia

\section{CONCLUSIONES}

La experiencia del proyecto ha permitido cumplir los objetivos planteados y extraer algunas conclusiones al respecto. La planificación de las actividades respondía a la triple fase característica de los itinerarios interdisciplinares donde el docente ha pasado de tener un papel eminentemente activo a ser un mero acompañante durante todo el proceso.

En un primer momento los alumnos, después de tomar conciencia de sus conocimientos en materia de geografía urbana subsanaron las posibles lagunas con el trabajo cooperativo grupal y la sesión de retroalimentación previa a la salida de campo. La consolidación y el asentamiento de las ideas básicas fue una cuestión capital. El reto de la investigación mediante la consulta y el vaciado de las fuentes bibliográficas ayudaron en la profundización en las técnicas de indagación. Con ello, se consiguió el objetivo planteado del fomento de las competencias investigadoras entroncando así con la ejecución de sencillas investigaciones sobre cuestiones de interés científico dentro y fuera del aula como recoge la guía docente de la asignatura.

En segundo lugar, la selección del barrio y su posterior desarrollo se presenta desde un enfoque globalizador, propio de las Ciencias Sociales. Al hablar del área de Ciencias Sociales, hay que superar la posible compartimentación y el aislacionismo de saberes. Para ello, el planteamiento del trabajo por proyectos con una metodología dinámica emanada del intercambio, de la construcción de los significados, y de la relación y convivencia entre los alumnos permitió ser una herramienta distinta y alternativa evitando un aferramiento al formato tradicional y apostando por el propio aprendizaje. La aportación de este tipo de trabajos radica en los significados a partir de la riqueza de aprendizajes manifestados en el aula (constructivismo, descubrimiento, colaborativo, significativo, globalización) haciendo especial hincapié en una memorización comprensiva y no repetitiva de los conocimientos (Gómez y Delgado, 2019). Los resultados obtenidos, en este sentido, fueron muy satisfactorios con 
el nivel adquirido en las producciones grupales abarcando los subapartados en que se dividió el trabajo del barrio hasta el punto de que fueron más de 26 las fuentes bibliográficas consultadas (documentales, gráficas, hemerográficas y estadísticas). De hecho, el objetivo fundamental de valorar el potencial de un sector de la ciudad, en el sentido de conocer en profundidad las características históricas, sociales, económicas y culturales de la barriada mediante una investigación sobre la realidad urbana desde un prisma geográfico, se consiguió sobradamente con los trabajos presentados por los alumnos. Hay que decir, que los resultados elaborados por los estudiantes mostraron elevadas cotas de motivación e interés a lo largo de todo el proceso.

Finalmente, la salida de campo, como actividad recapituladora mediante la observación directa ha permitido en este proyecto, interrelacionar lo aprendido en el aula con lo observado en el espacio a través del análisis DAFO y de las encuestas de percepción. Los resultados de las mismas desvelan el grado de consecución de las competencias geográficas en su conjunto. La toma de contacto en el trabajo de campo a través de las técnicas de la entrevista permitió a los estudiantes contemplar in situ el tipo de plano urbano dominante, los volúmenes y las técnicas constructivas empleadas en las viviendas superando la realidad facilitada por los navegadores web. El paseo por el barrio permitió empatizar con los principales problemas sociales, económicos y urbanos traducidos en sus propias aportaciones sobre las ventajas y desventajas del barrio. Con esta estrategia didáctica, los futuros maestros consiguen alcanzar las capacidades para comprender, entender y valorar la ciudad y su patrimonio construido partiendo de los conceptos espacio-temporales y en un escenario de aprendizaje informal. Por ello, además de conocer el medio desde un punto de vista conceptual y descriptivo es necesario el fomento de una actitud crítica hacia los problemas sociales latentes entre los vecinos.

\section{Referencias}

Butts, M. (1930). Los centros de interés, los "proyectos" y la simplificación del empleo del tiempo. Boletín de la Institución Libre de Enseñanza, año LIV, 353-357.

Cambil Hernández, M. de la E. (2015). La ciudad como recurso para la enseñanza aprendizaje del patrimonio cultural. Opcion, 31(Special Issue 3), 295-319. Recuperado de https://www.redalyc.org/pdf/310/31045567016.pdf

Cano de la Cuadra, J. y Navarro Martínez de la Casa, A. (2012). Propuesta didáctica sobre los pueblos de colonización agraria del Franquismo: el caso de Rinconada (Toledo) una vía para el desarrollo local. Clio: History and History Teaching, 38, 11-30.

Castellar, S. y Vilhena, J. (2011). O uso de diferentes linguagens em sala de aula. En S. Castellar y J. Vilhena (Eds.). Ensino de Geografia. (pp. 65-98). Sâo Paulo: Cengage Learning.

De Lázaro y Torres, M. L. (2013). El impulso de las competencias espaciales a través del trabajo de campo virtual en las ciudades. En AA.VV. (Ed.), A cidade, um laboratório para a educaçao geográfica (pp. 35-61). Lisboa: Associação de Professores de Geografia

De Souza Cavalcanti, L. (2020). Formar para a vida urbana cidadã como meta para o professor de Geografia: aportes teóricos e ensinamentos da experiência. AGALI Journal, 10, 45-64.

De Souza Cavalcanti, L. y de Souza, V. C. (2014). A formação do professor de geografia para atuar na educação cidadã. Scripta Nova: revista electrónica de Geografía y Ciencias Sociales, nº. extra 18, 496, 2014.

García de la Vega, A. (2004). El itinerario geográfico como recurso didáctico para la valoración del paisaje. Didáctica Geográfica, 79-95. Recuperado de http://www.didacticageografica.es/index.php/didacticageografica/article/viewFile/182/173

García Marchante, J. S. (1978). El poblado Obispo Laplana. Cuenca, 13, 39-60. 
García Ruiz, A. L. (1994). Los itinerarios didácticos: una de las claves para la enseñanza y comprensión de la Geografía. Íber. Didáctica de Las Ciencias Sociales, Geografía e Historia, $1,117-125$.

Gilio, B. (2015). El uso de la cartografía y la toponimia como recursos didácticos en la enseñanza secundaria de geografía: análisis de una experiencia áulica. Informes Científicos Técnicos UNPA, 7(1), 121-143.

Godoy, I. y Sánchez, A. (2007): El trabajo de campo en la enseñanza de la Geografía, Sapiens, Revista Universitaria de Investigación, 2(8), 137-146.

Gómez Hurtado, I., y Delgado Algarra, E. J. (2019). Aprender a enseñar el patrimonio desde la metodología de trabajo por proyectos. una experiencia en el grado de educación. En M. J. Hortas, A. Dias y N. De Alba (Eds.), Enseñar y aprender didáctica de las ciencias sociales: la formación del profesorado desde una perspectiva sociocrítica (pp. 872-880), Lisboa: Ediciones Escola Superior de Educação, Instituto Politécnico de Lisboa, AUPDCS.

Gurevich, R. (2009) Educar en tiempos contemporáneos: una práctica social situada. Propuesta educativa, 32, 23-31.

Insa, Y. (2002). Itinerarios urbanos, recursos y materiales didácticos para explicar la ciudad. Iber: Didáctica de Las Ciencias Sociales, Geografía e Historia, 32, 89-95.

Lock, R. (1998). Fieldwork in the life sciences. International Journal of Science Education, 20(6), 633-642. DOI: 10.1080/0950069980200602

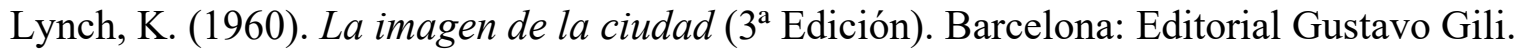

Millán Escriche, M. (2004). La geografía de la percepción: una metodología de análisis para el desarrollo rural. Papeles de Geografia, 40, 133-149.

Mínguez García, M. del C. (2010). Enseñar la ciudad a través de sus calles. El caso de Sevilla. En $\mathrm{M}^{\mathrm{a}}$. J. Marrón Gaite y $\mathrm{M}^{\mathrm{a}} \mathrm{L}$. de Lázaro y Torres (Eds.) Geografía, educación y formación del profesorado en el marco del espacio europeo de educación superior. Volumen II (pp. 531543), Madrid: Grupo de Didáctica de la AGE, Departamento de Didáctica de las Ciencias Sociales y Universidad Complutense.

Morales Hernández, A. J., Souto González, X. M. y Caurín Alonso, C. (2013). Los trabajos de campo en la formación docente: los estudios de caso. En AA. VV (eds.). Atas do VI Congresso Ibérico de Geografia, A cidade, um laboratório para a educação geográfica (pp. 463-478), Lisboa: Associação de Professores de Geografia y Associación de Geógrafos Españoles Grupo de Didática de la Geografia.

Morales Yago, F. J. (2012). La geografía de la percepción: una metodología válida aplicada al caso de una ciudad de tipo medio-pequeño. El ejemplo de Yecla (Murcia). Papeles de Geografía, $55-56,137-152$.

Pastor Blázquez, M. M. (2004). Estrategias y métodos didácticos para la enseñanza de las Ciencias Sociales. En M. C. Domínguez Garrido (Ed.), Didáctica de las Ciencias Sociales (pp. 147203). Madrid: Person Educación.

Pérez de Sánchez, A. G. y Rodríguez Pizzinato, L. A. (2006). La salida de campo, una manera de enseñar y aprender geografía. Geoenseñanza, 11, 229-234.

Pozuelos Estrada, F. J. (2007). Trabajo por proyectos en el aula: descripción, investigación y experiencias. Morón de la Frontera (Sevilla): Movimiento Cooperativo de Escuela Popular.

Santolaria Botet, A. (2014). La ciudad como recurso didáctico. Edetania: Estudios y Propuestas Socio-Educativas, 45, 235-244.

Soares da Mota Duarte, C. (2011) O lugar e o barrio no ensino de geografia: refletindo sobre situaçôes de ensino en uma escola da periferia de Ubelândia-MG. Ensino de Geografia, 3(2), 113-136.

Sousa Fernandes, S.A., García Monteagudo, D. y Souto González, X. M. (2016). Educación geográfica y las salidas de campo como estrategia didáctica: un estudio comparativo desde el Geoforo Iberoamericano. Biblio3W, Revista bibliográfica de geografía y ciencias sociales, $X X I(1155)$. 
Tejuca, J. (2016). El municipio: visita a nuestro ayuntamiento. Iber: Didáctica de Las Ciencias Sociales, Geografía e Historia, 82, 20-26.

Urteaga González, L., y Capel Sáez, H. (1982). La geografía y la didáctica del medio urbano. Revista de Geografía, 16(16), 113-128.

Valero, L. y de Miguel González, C. (1956). Los poblados de absorción de Madrid. Revista Nacional de Arquitectura, 176-177, 45-49.

Valverde Ortega, J. Á. (2001). El planeamiento urbano como recurso didáctico para la enseñanza de la ciudad. En Ma J. Marrón Gaite (Ed.), La formación geográfica en los ciudadanos en el cambio de milenio (pp. 3661-371). Grupo de Didáctica de la AGE, Associação de profesores de geografía de Portugal y Universidad Complutense de Madrid.

Vicent, N. y Luna, Ú. (2019). Educación emocional y patrimonio en el aula. Un proyecto para la formación del profesorado de Educación Primaria. En M. J. Hortas, A. Dias y N. de Alba (Eds.), Enseñanza y aprender didáctica de las ciencias sociales: la formación del profesorado desde una perspectiva sociocrítica (pp. 881-888). Ediciones Escola Superior de Educação, Instituto Politécnico de Lisboa, AUPDCS.

Vilarrasa Cunillé, A. (1999). Les sortides escolars: viatge cap al coneixement. Guix: Elements d'acció educativa, 251,41-46

Vilarrasa Cunillé, A. (2002). El medio del ciudadano del siglo XXI. Iber: Didáctica de Las Ciencias Sociales, Geografía e Historia, 32, 41-49.

Vilarrasa Cunillé, A. (2005). El medio local como escala de análisis en la didáctica de las ciencias sociales de educación secundaria. Enseñanza de las Ciencias Sociales, 4,11-19

\section{Cómo CITAR ESTE ARTÍ́CULO}

Serrano Gil, O. (2021). Experiencia didáctica dentro y fuera del aula: un itinerario interdisciplinar para conocer un barrio de la ciudad de Cuenca. Didáctica de las ciencias experimentales y sociales, 41, 39-56. DOI: 10.7203/DCES.41.18420. 